\title{
Zeolite Based Air Electrodes for Secondary Batteries
}

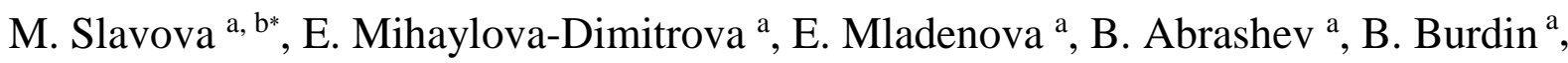 \\ D. Vladikova ${ }^{\text {a }}$ \\ ${ }^{a}$ Institute of Electrochemistry and Energy Systems “Academician Evgeni Budevski”, Acad. Georgi Bonchev 10 Str., 1113 Sofia, Bulgaria \\ b "Todor Kableshkov” University of Transport, 158 Geo Milev Str., 1574 Sofia, Bulgaria
}

\begin{abstract}
In recent years, secondary batteries received considerable attention as promising technology for energy storage in combination with renewable energy sources. The oxidation of carbon in conventional air electrodes reduces the life of secondary batteries. One possible solution for overcoming this problem is the replacement of carbon material with zeolite.

Zeolite is a natural or synthetic porous material with crystalline structure which provides the necessary gas permeability. The required hydrophobicity of the electrode is ensured by mixing zeolite with an appropriate amount of polytetrafluoroethylene following a specially developed procedure. The main purpose of the present research is to discover the optimum level of hydrophobicity (impregnation) of zeolite. Moreover, appropriate amount of PTFE will ensure better mechanical stability and long charge/discharge cycle life.

The results from this study show that the replacement of carbon with zeolite in the gas diffusion layer is a promising direction for optimization of the bi-functional air electrode. The relationship between the particle size and the hydrophobicity of the electrode was found. It was found that the mechanical stability and hydrophobicity of the electrode improved with the replacement of the emulsion powder. The gas permeability is maintained in the norms, which guarantees the good performance of the electrode. More than 200 charge/discharge cycles were reached.
\end{abstract}

\section{Keywords:}

Carbon-free Air Electrodes;

Zeolite;

Gas Diffusion Electrode;

Secondary Metal-air Batteries.

\section{Article History:}

Received: 05 December 2019

Accepted: 21 January 2020

Published: 01 February 2020

\section{1- Introduction}

In order to turn Renewable Energy Sources (RES) into a main energy source it is necessary to store the produced energy, which thus requires "innovative solutions, next-generation technologies, including potentially revolutionary technologies" [1]. Batteries have an important role in integrating and optimizing the application of RES. Electrically rechargeable metal-air and metal-hydride air batteries are very attractive as a candidate for energy storage materials due to their low cost and high stability in an aqueous solution. They are environmentally friendly and would theoretically allow for a high specific energy [2-5]. Concentrated potassium hydroxide is the electrolyte of choice for metal-air rechargeable batteries such as the zinc-air and iron-air batteries. In order to operate properly, metal hydride-air systems require bi-functional air electrodes. One technological solution is to develop zinc-air batteries, because of their extremely high potential use. Research in this area paves the way for further industrial production.

Metal-air system is a hybrid electrochemical structure which combines a metal anode and a gas-diffusion cathode, similar to that used in fuel cells. Its main advantage is the use of oxygen from the atmospheric air [6]. The development of rechargeable $\mathrm{Zn}$-air batteries is a topic of current interest, due to the advantages of the system to ensure high energy density and capacity at low price [7-9]. However, there are still no effectively operating secondary metal-air batteries which make this topic attractive for necessary further research, which should be focused on improvements of the

\footnotetext{
* CONTACT: Mslavova@iees.bas.bg

DOI: http://dx.doi.org/10.28991/esj-2020-01206
}

(C) 2019 by the authors. Licensee ESJ, Italy. This is an open access article under the terms and conditions of the Creative Commons Attribution (CC-BY) license (https://creativecommons.org/licenses/by/4.0/). 
recharging, enhancement of durability and reduction of costs [10]. The advantages of the system are: inexpensive, nontoxic materials, operation in humid environments and water-based electrolytes, low self-discharge, recyclability, simple construction, long life and "flat" discharge curves [11, 12].

The components of the $\mathrm{Zn}$-air cell are: $\mathrm{Zn}$ electrode, alkaline electrolyte, separator and Air electrode (AE). The AE consists of a gas-diffusion layer (GDL) which ensures the needed oxygen and a bifunctional catalytic layer (CL) where the oxygen reduction/evolution takes place [10,13]. The classical GDL is made of carbon-based material and a hydrophobic binding material, typically polytetrafluoroethylene (PTFE). The optimization of its gas permeability and hydrophobicity is an important step in its preparation. The electrochemical reaction occurs at the triple-phase boundary electrode/ electrolyte/ gas phase. The active material in the GDE is oxygen from the ambient air and thus the air electrode does not "exhaust", i.e. it should work until it is mechanically damaged, e.g. caused by the oxidation of carbon [6]. During discharge, an oxygen reduction reaction (ORR) occurs, while the metal oxidizes and releases electrons which pass through the external net. In charge regime the opposite reactions with oxygen evolution take place. For a rechargeable gas diffusion electrode a bifunctional catalyst should be used in the CL layer. It needs to possess combination of good catalytic activity, electronic conductivity, good adhesion towards the GDL, and mechanical stability.

The main problem with the GDE is the high electrochemical carbon corrosion during oxygen evolution reaction (OER), which reduces its stability [14-19].

One of the possible solutions is the replacement of the carbon black in the GDL with a material with a similar porous structure as that of the zeolite. There is no information for such replacement in the literature, although zeolites are used in batteries as molecular sieves that can protect metal electrodes from rupture. Zeolites are a large group of alumosilicates with a crystalline structure which forms evenly distributed voids and channels -20 to $50 \%$. The group consists of more than 50 naturals and 1400 synthetic minerals. They are soft minerals with a three-dimensional frame of interconnected tetrahedra, containing Al, Si and O [20]. In Bulgaria, in the region of Kardzhali there are large deposits of zeolite of the type clinoptiolite. It has a honeycomb-like structure, an active area of over $450 \mathrm{~m}^{2} / \mathrm{g}$ and an average pore size of $4.6 \mathrm{~nm}$ [21].

The aim of this work is the development of innovative zeolite based carbon-free gas diffusion electrodes for rechargeable metal-air batteries. The selected approach replaces the carbon based GDL with zeolite based one.

\section{2- Experimental}

The zeolite-based AE consists of two layers - porous zeolite-based GDL and CL. The replacement of carbon black with zeolite of the type clinoptilolite was performed on a gas diffusion electrode described elsewhere [22]. For the preparation of the zeolite GDL zeolite powder with grain size up to $250 \mu \mathrm{m}$ was mixed with 20-60\% PTFE and hot pressed $\left(0.3 \mathrm{t} / \mathrm{cm}^{2}\right)$ at $250{ }^{\circ} \mathrm{C}$ for $3 \mathrm{~min}$. The bifunctional CL was a mixture of $\mathrm{Co}_{3} \mathrm{O}_{4}, \mathrm{Ag}$ and PTFE. The morphological studies were performed using Electron microscope JEOL 6390.

For fast evaluation of the hydrophobicity an empirical "water drop" test was introduced according to which the water drop should stay on the outer GDL surface for more than two hours for further testing of the sample (Figure 1a). The second leaking test was performed in a custom-made hydrophobicity test cell with electrolyte (6M KOH) for 100 hours (Figure 1b).
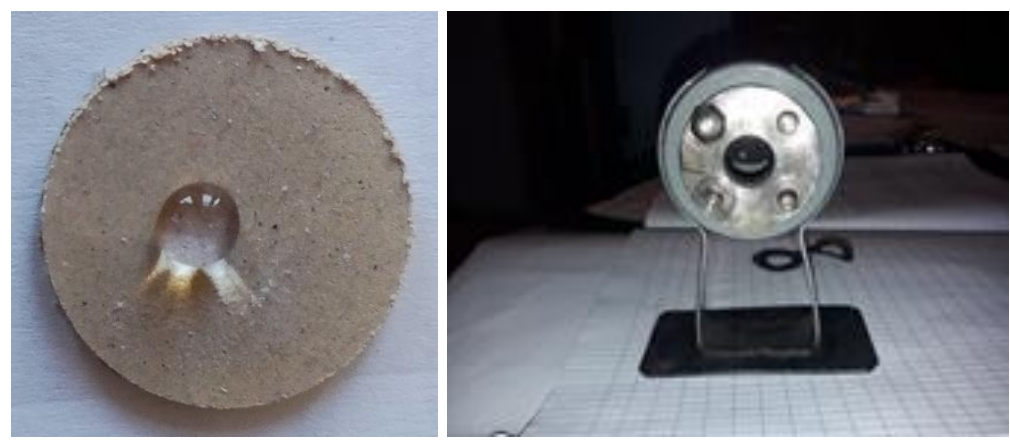

Figure 1. Hydrophobicity testing: a) water drop test and b) real conditions test.

For quick evaluation of the sample gas permeability, a simple testing system was used which gives a more realistic picture, reflecting the behavior of the percolating network. The methodology is based on measurements of the pressure $P\left(\mathrm{~mm} \mathrm{H}_{2} \mathrm{O}\right)$ dependence on the gas flow $q_{\text {flow }}[\mathrm{ml} / \mathrm{min}$ ] penetrating through porous media [17]. A new characteristic parameter named permeability resistance $R_{\mathrm{p}}$ (inversely proportional to the permeability) was introduced as an empirical criterion for the investigated system: the air permeability should not be less than $2.2 \mathrm{~mol} / \mathrm{min} / \mathrm{cm}^{2}$. 
The zeolite-based AEs with stainless steel current collectors were electrochemically tested in half-cell configuration at room temperature in $6 \mathrm{M} \mathrm{KOH}$. The AEs potential was measured vs. a hydrogen reference electrode (HRE). The electrode's working areas were respectively $1 \mathrm{~cm}^{2}$ for volt-ampere curves (VAC) measurements and $10 \mathrm{~cm}^{2}$ for charge/discharge cycling. Charge/discharge tests were performed on eight channel Galvanostat 54 (PMC) with a specialized electrochemical program, that allows potential evaluation within a pre-defined range with a given speed and current flow registration in parallel. A cycling was employed in the potential range $-1.0 \mathrm{~V}$ to $+2 \mathrm{~V}$. The charge time was $45 \mathrm{~min}$, the discharge time - $30 \mathrm{~min}$. The charge/discharge current density was $\pm 2 \mathrm{~mA} / \mathrm{cm}^{-2}$. Volt-ampere curves (VAC) were obtained using a Tacussel (Bi-PAD) galvanostat and voltmeter. The VACs results were compared with those for a carbon-based gas diffusion etalon electrode (EE) [23] with the same CL.

\section{3- Results and Discussion}

After the replacement of carbon-based material with zeolite in the classical GDL-recipe, PTFE-fibers crosslink the zeolite beans, which is a prerequisite for sufficient hydrophobicity (Figure 2).

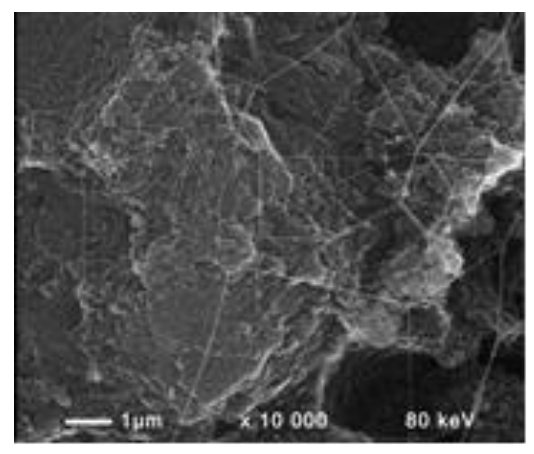

Figure 2. SEM image of zeolite-based GDL with $11 \mathrm{wt} \%$ PTFE.

However, samples with PTFE above 20 wt. \% show low air permeability and excellent hydrophobicity. The samples with $10 \div 20$ wt. \% PTFE powder have good gas permeability and mechanical stability, but still insufficient hydrophobicity. In order to fulfill both requirements, the teflonization procedure was modified and the Second generation GDL was developed. A procedure for impregnation by the introduction of a diluted emulsion on the surface of a GDL, carried out in several cycles, is introduced. It ensured the necessary hydrophobicity and gas permeability. The hydrophobicity increases as a result of the stepwise zeolite pores coating with PTFE. This technology was used for the preparation of GDEs with bifunctional CL $\left(20\right.$ wt. $\% \mathrm{Co}_{3} \mathrm{O}_{4}$ and 70 wt. \% $\mathrm{Ag}$ mixed with 10 wt. \% PTFE powder).

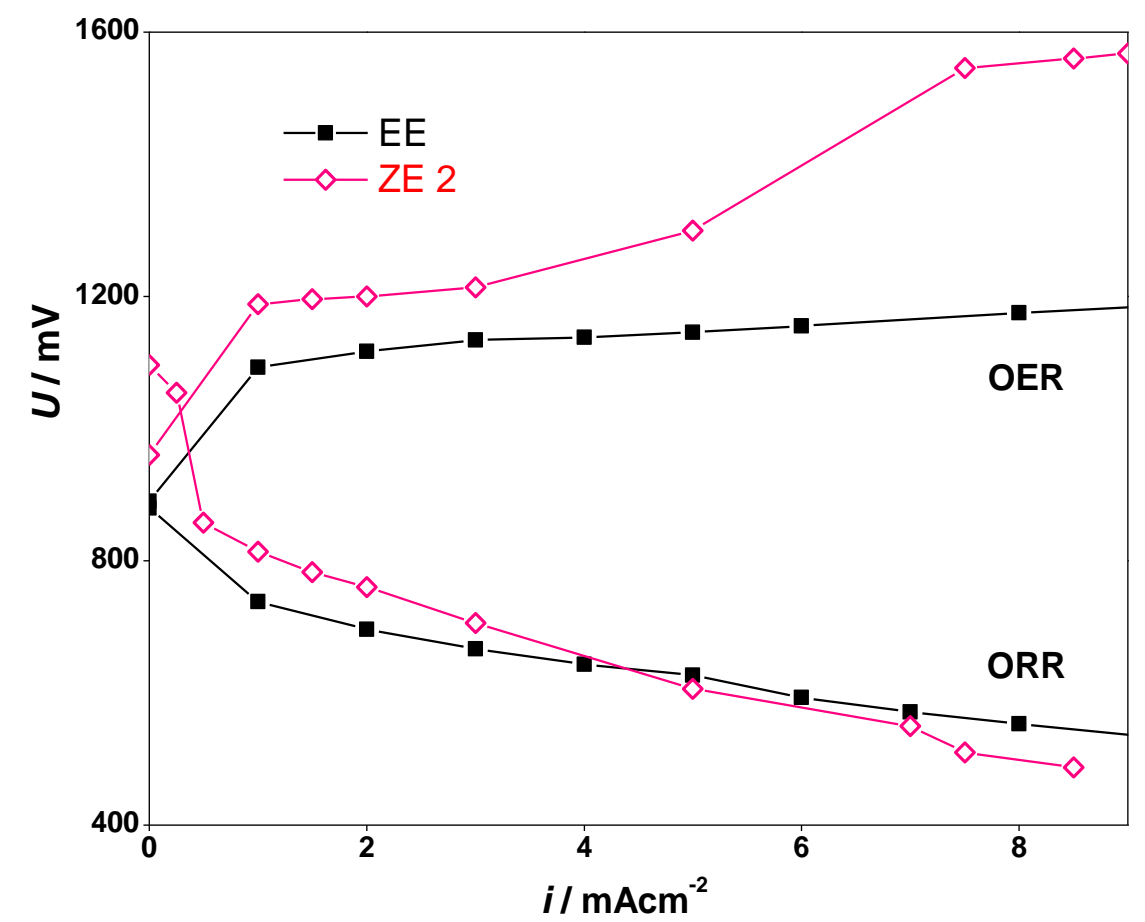

Figure 3. Volt-ampere characteristics during discharge (ORR) and charge (OER) measured on AE with impregnated zeolite-based GDL (ZE 2) compared with the etalon carbon-based GDE (EE). 
Although ZE 2 has similar behaviour as EE - up to $7 \mathrm{~mA} / \mathrm{cm}^{2}$ (Figure 3), its durability is low - it operates several cycles before wetting. The results presented in Figure 3 are similar to those obtained by Amin at al. [24]. For its improvment a second optimization of the hydrophobization procedure was performed.

Third generation GDL was developed, replacing the PTFE powder with diluted PTFE emulsion - PTFE emulsion was added to the powdered zeolite before hot pressing. The relationship between the particle size and the wetting of the electrode was found. With a zeolite particle size between 180 and $250 \mu \mathrm{m}$, the electrode has a poorer hydrophobicity than that obtained with zeolite with a particle size of up to $250 \mu \mathrm{m}$. This can be explained by the partial filling of large pores in the zeolite crystal lattice with smaller particles. This maintains oxygen permeability but reduces electrolyte leakage. Varying the ratio between the zeolite and PTFE emulsion was achieved a good balance between hydrophobicity and gas permeability. That increased the number of charge/discharge cycles (Figure 4).

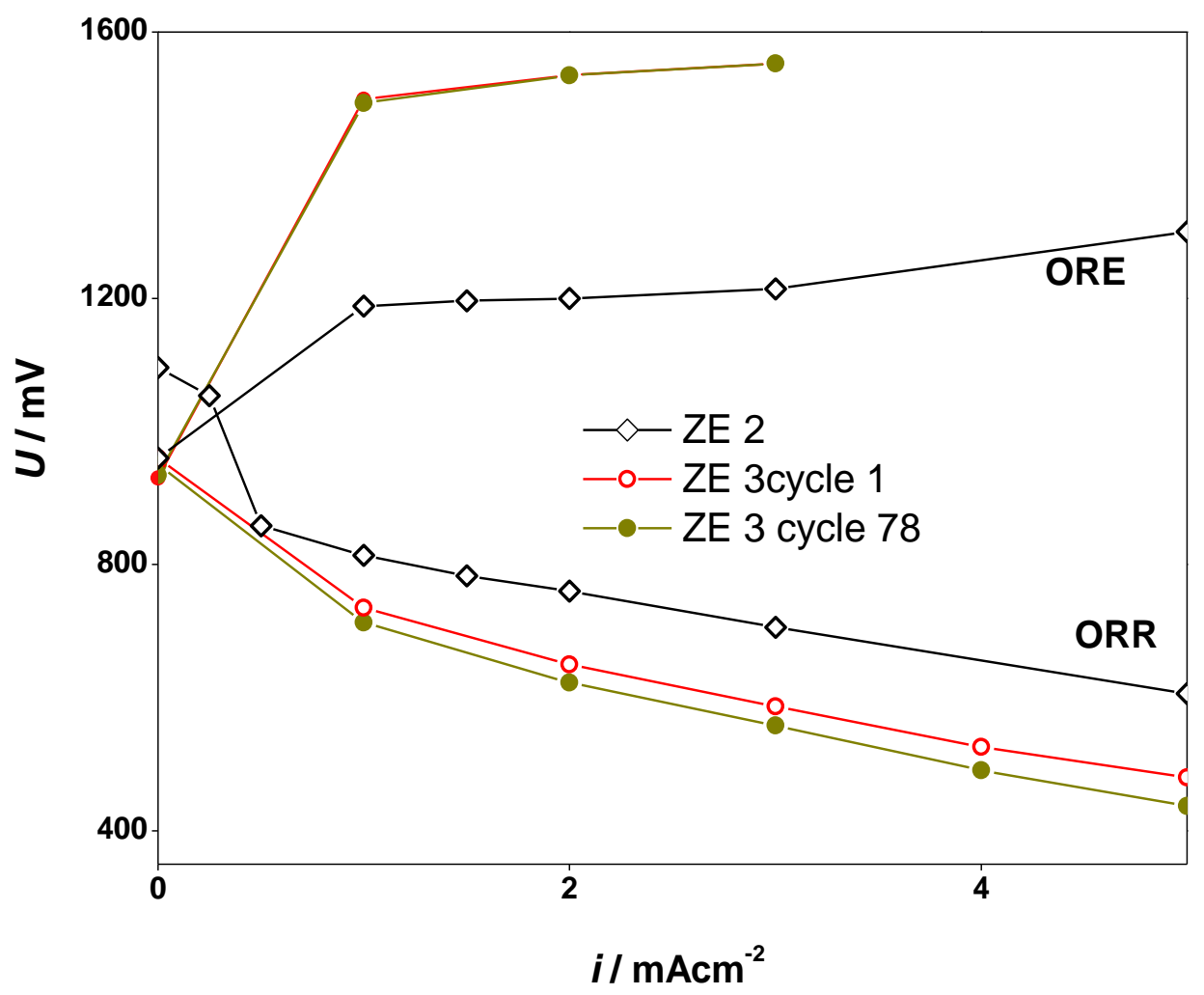

Figure 4. Volt-ampere characteristics of third-generation zeolite-based AE (ZE 3) during discharge and charge compared with ZE 2.

The current density about $2-5 \mathrm{~mA} / \mathrm{cm}^{2}$ is a promising initial result, taking into account the requirements for the final usage of $\mathrm{Zn}$-air batteries in solar farms, where they operate in combination with other batteries/supercapacitors [10].

It was found that the replacement of the PTFE powder with PTFE emulsion leads to an improvement in the mechanical stability and hydrophobicity of the electrode. The gas permeability is maintained in the norms that ensure electrode operation. As it is shown in Figure 5, the third-generation zeolite-based AE was stable during charge/discharge cycling for over 200 cycles.

It was found that small microstructural changes have a significant effect on the mechanical stability of the material under study. In this case, zeolite with a particle size of up to $250 \mu \mathrm{m}$ shows good cycling performance - more than 200 charge/ discharge cycles. 


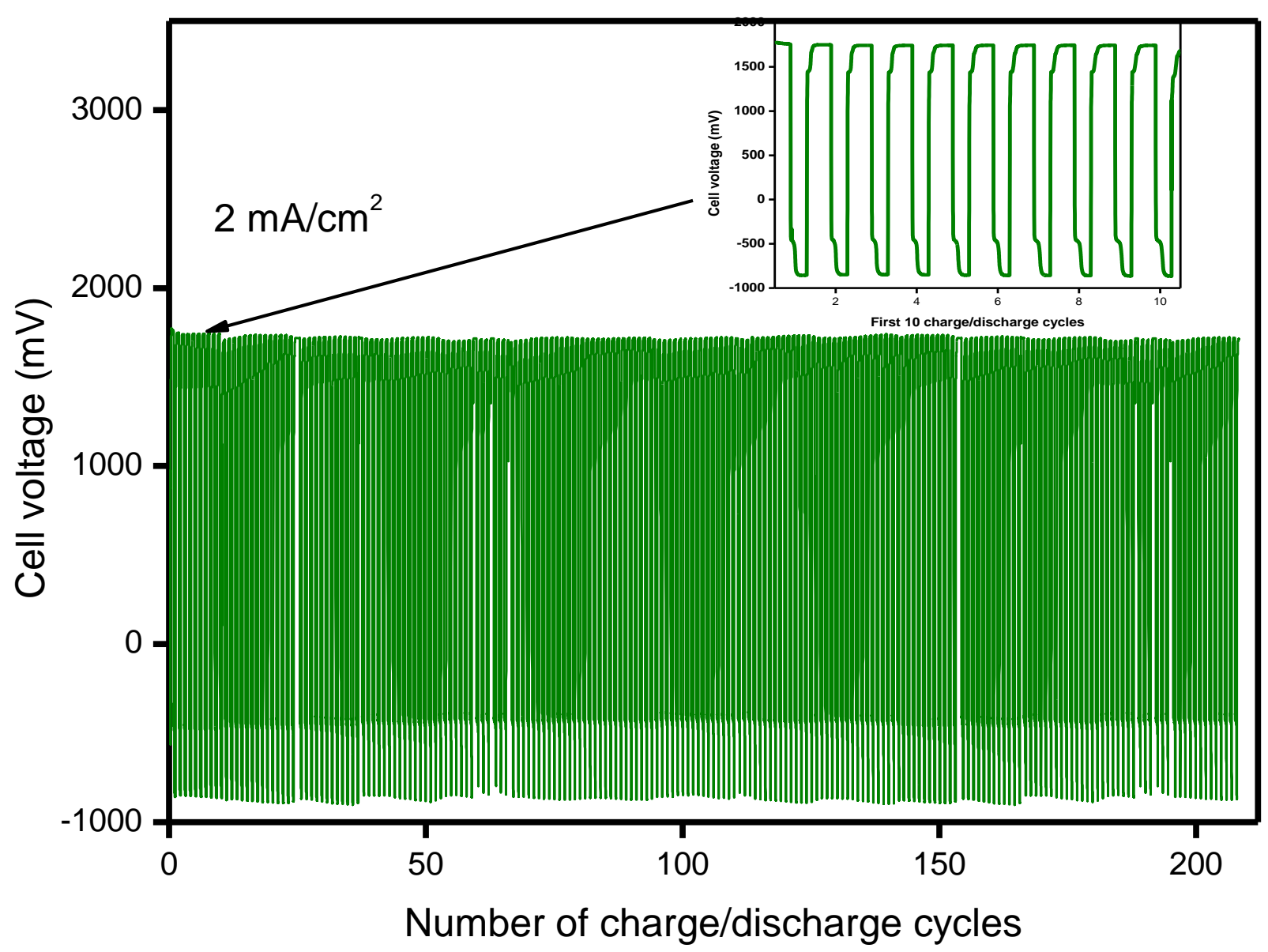

Figure 5. Charge/discharge cycling of third-generation zeolite-based AE at: charge time 45 min; discharge time 30 min; current density: $\pm 2 \mathrm{~mA} / \mathrm{cm}^{2}$.

\section{4- Conclusion}

Theprimery results obtained on the development of carbon-free air electrode replacing carbon-based materials with zeolite are promising in respect to both the current densities reached and the number of cycles. In addition, zeolites are available, lightweight, porous, and cheap materials with a crystalline structure, making them an attractive option for the replacement of the carbon-black in the gas diffusion layer for secondary metal-air batteries. In this study, the optimum level of hydrophobicity (impregnation) and gas permeability of the zeolite used to make the gas diffusion layer of secondary metal-air batteries was established. In addition, optimizing the amount of PTFE guarantees better mechanical stability, good oxygen permeability and longer charge/ discharge cycle times.

A relationship was found between the zeolite particle size and hydrophobicity, as well as the mechanical stability of the electrode. The removal of particles smaller than $180 \mu \mathrm{m}$ and the hydrophobicity and mechanical stability of the prepared electrodes decreased significantly.

It was found that the mechanical stability and hydrophobicity of the electrode improved with the replacement of the emulsion powder. The gas permeability is maintained within the norms, which guarantee the good performance of the electrode. The achieved current density of about $2-5 \mathrm{~mA} / \mathrm{cm}^{2}$ is a promising initial result, given the requirements for using metal-air batteries in solar farms where they work in combination with other types of batteries or supercapacitors.

The next stage of the optimization of the zeolite-based secondary metal-air electrode is focused on further increase of the current density and number of charge/discharge cycles, i.e. durability and scale up. Zeolite electrodes with other noble metal-free bifunctional catalysts will also be tested.

\section{5- Funding}

This work was supported by the Bulgarian Ministry of Education and Science under the National Research Programme E+: Low Carbon Energy for the Transport and Households, grant agreement D01-214/2018 and the National Roadmap for Research Infrastructure (2017-2023): Research Infrastructure Energy Storage and Hydrogen Energetics NI SEVE, grant agreement D01-160/28.08.18. 


\section{6- Conflict of Interest}

The author declares that there is no conflict of interests regarding the publication of this manuscript. In addition, the ethical issues, including plagiarism, informed consent, misconduct, data fabrication and/or falsification, double publication and/or submission, and redundancies have been completely observed by the authors.

\section{7- References}

[1] Accelerating Clean Energy Innovation, C. O. M. "763 final, 30.11.2016." European Commission, Brussels (2016). Available online: http://ec.europa.eu/energy/sites/ener/files/documents/1_en_act_part1_v6_0.pdf.

[2] Dong, Hanwu, Yohannes Kiros, and Dag Noréus. “An Air-metal Hydride Battery Using MmNi3.6Mn0.4Al0.3Co0.7 in the Anode and a Perovskite in the Cathode." International Journal of Hydrogen Energy 35, no. 9 (May 2010): 4336-4341. doi:10.1016/j.ijhydene.2010.02.007.

[3] Hosni, B., C. Khaldi, O. ElKedim, N. Fenineche, and J. Lamloumi. "Structure and Electrochemical Hydrogen Storage Properties of Ti-Fe-Mn Alloys for Ni-MH Accumulator Applications.” Journal of Alloys and Compounds 781 (April 2019): 1159-1168. doi:10.1016/j.jallcom.2018.12.159.

[4] Pei, Pucheng, Shangwei Huang, Dongfang Chen, Yuehua Li, Ziyao Wu, Peng Ren, Keliang Wang, and Xiaoning Jia. “A HighEnergy-Density and Long-Stable-Performance Zinc-Air Fuel Cell System.” Applied Energy 241 (May 2019): 124-129. doi:10.1016/j.apenergy.2019.03.004.

[5] Paulraj, Alagar, Yohannes Kiros, Mats Göthelid, and Malin Johansson. "NiFeOx as a Bifunctional Electrocatalyst for Oxygen Reduction (OR) and Evolution (OE) Reaction in Alkaline Media." Catalysts 8, no. 8 (August 10, 2018 ): 328. doi:10.3390/catal8080328.

[6] A. Kaisheva, in: Portable and Emergency Energy Sources, Z. Stoynov and D. Vladikova (Eds.), Marin Drinov Academic Publishing House, Sofia, Bulgaria, (2006): 301-328.

[7] A European Strategy for Low-Emission Mobility, C. O. M. "501 final, 20.07.2016." European Commission, Brussels (2016). Available online: https://ec.europa.eu/transparency/regdoc/rep/1/2016/EN/1-2016-501-EN-F1-1.PDF.

[8] Gu, Peng, Mingbo Zheng, Qunxing Zhao, Xiao Xiao, Huaiguo Xue, and Huan Pang. "Rechargeable Zinc-air Batteries: a Promising Way to Green Energy.” Journal of Materials Chemistry A 5, no. 17 (2017): 7651-7666. doi:10.1039/c7ta01693j.

[9] Fu, Jing, Zachary Paul Cano, Moon Gyu Park, Aiping Yu, Michael Fowler, and Zhongwei Chen. "Electrically Rechargeable ZincAir Batteries: Progress, Challenges, and Perspectives." Advanced Materials 29, no. 7 (November 28, 2016 ): 1604685. doi:10.1002/adma.201604685.

[10] EU funded H2020 project „Zinc-Air Secondary innovative nanotech based batteries for efficient energy storage”- ZAS (GA 646186) (http://sintef.no/projectweb/zas/).

[11] Lee, Jang-Soo, Sun Tai Kim, Ruiguo Cao, Nam-Soon Choi, Meilin Liu, Kyu Tae Lee, and Jaephil Cho. "Metal-Air Batteries with High Energy Density: Li-Air Versus Zn-Air.” Advanced Energy Materials 1, no. 1 (December 8, 2010): 34-50. doi:10.1002/aenm.201000010.

[12] Z. Stoynov, D. Vladikova (Eds.), Portable and Emergency Energy Sources, Marin Drinov Academic Publishing House, Sofia, Bulgaria, 2006.

[13] Zhang, X. Gregory. “Fibrous Zinc Anodes for High Power Batteries.” Journal of Power Sources 163, no. 1 (December 2006): 591-597. doi:10.1016/j.jpowsour.2006.09.034.

[14] Velraj, Samgopiraj, and Jiahong Zhu. "Carbon-Free NiCo2O4-Based Bifunctional Air Electrode for Rechargeable Metal-Air Batteries: Effect of the Spinel Crystallite Size." In Meeting Abstracts, no. 31, pp. 1500-1500. The Electrochemical Society, National Harbor, Maryland, USA, 2017.

[15] Kar, Mega, Bjorn Winther-Jensen, Maria Forsyth, and Douglas R. MacFarlane. "Chelating Ionic Liquids for Reversible Zinc Electrochemistry.” Physical Chemistry Chemical Physics 15, no. 19 (2013): 7191. doi:10.1039/c3cp51102b.

[16] Müller, S., F. Holzer, and O. Haas. "Optimized zinc electrode for the rechargeable zinc-air battery." Journal of applied electrochemistry 28, no. 9 (1998): 895-898. doi:10.1023/A:1003464011815.

[17] O. Haas, JV. Wesemael, in: Encyclopedia of Electrochemical Power Sources, J Garche, Elsevier Science, ISBN: 978-0-44452745-5, 2009, p. 384-392.

[18] Dunn, B., H. Kamath, and J.-M. Tarascon. "Electrical Energy Storage for the Grid: A Battery of Choices." Science 334, no. 6058 (November 17, 2011): 928-935. doi:10.1126/science.1212741.

[19] Caramia, Vincenzo, and Benedetto Bozzini. "Materials Science Aspects of Zinc-air Batteries: a Review." Materials for Renewable and Sustainable Energy 3, no. 2 (April 3, 2014). doi:10.1007/s40243-014-0028-3. 
[20] Kraljević Pavelić, Sandra, Jasmina Simović Medica, Darko Gumbarević, Ana Filošević, Nataša Pržulj, and Krešimir Pavelić. "Critical Review on Zeolite Clinoptilolite Safety and Medical Applications in Vivo." Frontiers in Pharmacology 9 (November 27, 2018): 1350. doi:10.3389/fphar.2018.01350.

[21] Moshoeshoe, Mohau, M. S. Nadiye-Tabbiruka, and V. Obuseng. "A review of the chemistry, structure, properties and applications of zeolites." Am. J. Mater. Sci 7, no. 5 (2017): 196-221.

[22] Abrashev, B., D. Uzun, H. Hristov, D. Nicheva, and K. Petrov. "Design of an electrochemical cell for Bi-functional Oxygen Electrode (BOE) studies." Advances in Natural Science: Theory and Applications 4, no. 2 (2016).

[23] Mladenova, E., D. Vladikova, Z. Stoynov, A. Chesnaud, A. Thorel, and M. Krapchanska. "Gases permeability study in dual membrane fuel cell." Bulgarian Chemical Communications 45, no. 3 (2013): 366-370.

[24] Amin, Hatem M.A., Helmut Baltruschat, Dennis Wittmaier, and K.Andreas Friedrich. "A Highly Efficient Bifunctional Catalyst for Alkaline Air-Electrodes Based on a Ag and Co3O4 Hybrid: RRDE and Online DEMS Insights." Electrochimica Acta 151 (January 2015): 332-339. doi:10.1016/j.electacta.2014.11.017. 